\title{
ANALISA KETANGGUHAN KOMPOSIT ALUMINIUM BERPENGUAT SERBUK SiC
}

\author{
Suyanto \\ Program Studi Teknik Bangunan Kapal \\ Akademi Teknik Perkapalan (ATP) Veteran Semarang \\ Email: suyantoeste@yahoo.com
}

\begin{abstract}
ABSTRAK
Produksi AMC yang diperkuat SiC adalah untuk memadukan sifat mekanik aluminium yang ulet dan ringan dengan sifat $\mathrm{SiC}$ yang keras. Diantara sifat material yang diinginkan adalah tangguh dan ringan. Penilitian ini bertujuan untuk menganalisa ketangguhan komposit aluminium berpenguat serbuk $\mathrm{SiC}$ yang dibuat dengan metode semi solid stir casting. Analisa ketangguhan dilakukan dengan dua pendekatan, yaitu analisa ketangguhan dari hasil uji tarik dan hasil uji impak. Dari hasil penelitian disimpulkan bahwa penambaha $\mathrm{SiC}$ hingga 5\% mampu meningkatkan ketangguhan komposit Al-SiC. Pada penambahan SiC lebih dari 5\% ketangguhann mengalami penurunan.
\end{abstract}

Kata kunci: AMC, SiC, ketangguhan.

\section{ABSTRACT}

AMC production with $\mathrm{SiC}$ as reinforcement has a purpose to combine the mechanical properties of aluminum and SiC. Among the desired material properties is tough and lightweight. This research aims to analyze the toughness of the composite aluminum reinforced SiC powder made by semi-solid casting methood. wheel This research use semi-solid stir casting methood. Toughness analysis done by two approaches, namely toughness analysis of tensile test curve and impact test results. The conclusion is that adding SiC up to 5\% can improve the toughness of the AMC. The toughness is decrease in addition more than $5 \% \mathrm{SiC}$.

Keywords: AMC, SiC, toughness

\section{PENDAHULUAN}

AMC (Aluminum Matrix Composites) adalah jenis material komposit logam dengan aluminium sebagai matrik dan serbuk SiC sebagai penguat. AMC mempunyai prospek pengembangan yang bagus, didasari oleh sifat-sifatnya yang baik, seperti kekerasan dan kekuatan yang tinggi, mampu mesin yang baik, densitas yang rendah, bahan dasar yang mudah didapatkan, dengan harga yang ekonomis dan bersaing dengan material lain. AMC banyak dimanfaatkan pada bidang industri otomotif, penerbangan, dan pertahanan sebagai bahan kendaraan tempur yang membutuhkan performa tinggi. AMC bisa diaplikasi dalam permesinan pesawat terbang, dan aplikasi dalam industri otomotif [1].

Proses pembuatan AMC dengan cara penegcoran mempunyai beberapa kelemahan diantaranya adalah sulitnya terjadi pencampuran partikel $\mathrm{SiC}$ ke dalam aluminium cair karena partikel $\mathrm{SiC}$ sulit terbasahi permukaannya oleh aluminium cair. Masalah lainnya adalah kecenderungan partikel SiC mengendap di dasar matrik aluminium cair. Hal tersebut menyebabkan distribusi SiC tidak seragam dan akan berpengaruh terhadap sifat mekanik AMC yang dihasilkan, sehingga sifat mekanik bahan yang diinginkan tidak bisa tercapai.

Beberapa penelitian dilakukan untuk mengatasi permasalahan pada pengecoran aluminium berpenguat $\mathrm{SiC}$. Salah satu metode yang dipakai adalah teknik stir casting menggunakan pengadukan dengan putaran tinggi dan dengan pemanasan awal terhadap partikel keramik agar bisa terbasahi oleh matrik cair, sebelum dicampurkan ke dalam matrik. Tujuan utamanya adalah untuk mendapatkan distribusi partikel keramik yang seragam [2]. Pengadukan mekanik diperlukan untuk meningkatkan wettability. Pengadukan pada kondisi cair sempurna mengakibatkan partikel penguat mengapung di permukaan matrik cair. Pengadukan pada kondisi semi solid bisa membantu penyatuan matrik dan penguat, namun harus dipanaskan lagi sampai suhu penuangan [3].

Produksi AMC yang diperkuat SiC mempunyai target memadukan sifat mekanik aluminium dan $\mathrm{SiC}$. Kelebihan aluminium adalah ringan (masa jenis $2,7 \mathrm{gram} / \mathrm{cm}^{3}$ ), tahan korosi, dan mempunyai sifsat 
mampu cor yangbaik. Namun untuk aplikasi tertentu beberapa sifat mekanik aluminium perlu ditingkatkan diantaranya sifat kekuatan dan ketangguhan. Ketangguhan adalah kemampuan material untuk mengalami deformasi plastis dan menyerap energi dalam proses deformasi hingga mengalami perpatahan. Yang menjadi inti adalah besarnya energi yang disesap sebelum patah. Ketangguhan mempunyai relasi dengan kekuatan dan keuletan. Dengan kata lain suatu material yang mempunyai kekuatan dan keuletan tinggi akan mempunyai ketangguhan yang tinggi pula. Demikian pula sebaliknya material yang mempunyai kekuatan dan keuletan rendah akan memiliki ketangguhan yang rendah.

Salah satu cara untuk mengukur ketangguhan material adalah dengan cara menghitung luasan dibawah kurva tegangan-regangan hasil uji tarik. Nilai tersebut disebut "ketangguhan material" yang memiliki satuan energi per volume [4]. Luas ini menunjukkan jumlah energy persatuan volume yang dapat di kenakan kepada material tanpa mengakibatkan material tersebut rusak atau patah. Terdapat beberapa cara untuk menentukan luas daerah dibawah kurva tegangan regangan. Untuk menentukan luasan dibawah kurva tegangan-regangan hasil uji tarik bisa digunakan cara sederhana yaitu dengan menghitung luasan di bawah kurva dengan metode segitiga atau metode trapesium.

Nilai ketangguhan material juga bisa didapatkan dengan pengujian impak. Ketangguhan material yang diperoleh dengan pengujian impak menunjukkan energi yang dibutuhkan untuk mematahkan spesimen atau energi yang diserap spesimen hingga mengalami patah. Prinsip kerja uji impak menggunakan hukum kekekalan energi. Standar pengujian impak untuk matrial logam bisa mengacu pada ASTM E 23 [5].

Tulisan ini akan menyajikan pembuatan AMC berpenguat $\mathrm{SiC}$ dengan proses stir casting dan pengadukan pada kondisi semi solid. Penambahan Mg sebagai wetting agent dilakukan agar aluminium cair bisa membasahi SiC. Pengujian impak dan tarik dilakukan untuk menganalisa ketangguhan AMC yang dihasilkan.

\section{TINJAUAN PUSTAKA}

Metode stirring pada logam cair atau metode vortex sangat menguntungkan untuk digunakan, karena bentuk casting hampir sama dengan produk akhir yang diinginkan, dan biaya produksi yang relatif rendah. Pada metode ini parameter yang berpengaruh terhadap hasil stir casting adalah ukuran serbuk atau partikel keramik, kemampuan dan ukuran impeler pengaduk, temperatur logam cair, waktu pengadukan, kecepatan pengadukan, kecepatan pemakanan partikel ke dalam campuran secara kontinyu dan dengan laju yang seragam, serta suhu cetakan [6].

Penelitian tentang komposit Al-SiC dengan menerapkan teknik stir casting dilakukan dengan menggunakan matrik A356, SiC divariasikan hingga prosentase 9\%. Dalam penelitian tersebut dilakukan pengadukan pada kondisi matrik cair sempurna. Partikel $\mathrm{SiC}$ sebagai penguat bisa tercampur dengan baik pada pengadukan kondisi cair [7]. Aluminum Matrik Composites dengan SiC 10\% berhasil dibuat dengan dispersi $\mathrm{SiC}$ yang homogen dengan teknik pengadukan pada kondisi semi solid. Ada beberapa poin yang menjadi ketentuan dalam melakukan stir casting. Pengadukan mekanik diperlukan untuk meningkatkan wettability. Pengadukan pada kondisi cair sempurna mengakibatkan partikel penguat mengapung di permukaan matriks cair. Pengadukan pada kondisi semi solid bisa membantu penyatuan matrik dan penguat, namun harus dipanaskan lagi sampai suhu penuangan [3].

Penelitian untuk mengetahui kekuatan impak komposit Al-SiC dilakukan oleh beberapa peneliti. Penelitian menggunakan matrik AlSi7Mg2 dengan penambahan partikel SiC 5\%, 10\%, dan 15\% masingmasing menghasilkan ketangguhan impak 0,38 J, 0,42 J, dan 0,58 J [8]. Ketangguhan komposit Al-SiC dengan matrik Al 6063 yang ditambah partikel SiC 5\%, 10\%, 15\%, dan 20\% berturut-turut sebesar 24 Nm, $26 \mathrm{Nm}, 29 \mathrm{Nm}$, dan $32 \mathrm{Nm}$ [9]. Penelitian menggunakan matrik Al 98,4\% dengan penambahan partikel SiC sebanyak 5\%, 10\%, 15\%, dan 20\% mendapatkan ketangguhan impak berturut-turut $22 \mathrm{Nm}$, $24 \mathrm{Nm}, 26 \mathrm{Nm}$, dan $27 \mathrm{Nm}$ [10]. Penelitian lain dengan matrik dan persentase penambahan SiC yang sama menghasilkan ketangguhan impak berturut-turut 22,67 J, $24 \mathrm{~J}, 27,33 \mathrm{~J}$, dan 31,33 J.

Penelitian menggunakan aluminum murni sebagai matrik juga dilakukan. Dengan penambahan $10 \%$ $\mathrm{SiC}$, ketangguhan impak yang dihasilkan adalah 8,7 Nm [11]. Penambahan $\mathrm{SiC} 5 \%, 10 \%$, dan 20\% pada aluminium murni menghasilkan ketangguhan impak berturut-turut 4,8 J, 5,2 J, dan 8,2 J [12]. Dari beberapa penelitian di atas bisa ditarik satu kesamaan bahwa kekuatan inpak meningkat seiring dengan meningkatnya penambahan $\mathrm{SiC}$ sampai kadar tertentu.

\section{METODE PENELITIAN}

Penelitian ini bertujuan untuk mengembangkan komposit bermatrik aluminium (Al-7Si) dengan penguat $\mathrm{SiC}$ dengan penambahan unsur $\mathrm{Mg}$ untuk meningkatkan wettability. Persen $\mathrm{SiC}$ yang 
ditambahkan adalah 5\%, 7,5\%, dan 10\% massa, sementara Mg ditambahkan sebanyak 1\% massa. Pembuatan komposit tersebut menggunakan proses semi solid stir casting. Fokus penelitian adalah mendapatkan parameter persentase $\mathrm{Mg}$ dan $\mathrm{SiC}$ yang sesuai untuk mendapatkan dispersi partikel SiC yang seragam dan wettability yang baik.

\subsection{Proses Stir Casting}

Proses yang dilakukan stir casting adalah sebagai berikut :

1) Melakukan persiapan bahan-bahan yang akan dilebur yaitu Al7Si ingot, dan Mg. Bahan-bahan tersebut dipotong-potong dengan mesin potong sampai berukuran kecil berdiameter sekitar $2 \mathrm{~cm}$. Hal ini dilakukan untuk memudahkan dalam pengaturan komposisi dan proses peleburan.

2) Masing-masing bahan ditimbang untuk mendapatkan komposisi massa sesuai dengan variasi. Adapun hasil penimbangan bahan untuk masing-masing variasi ditunjukkan pada Tabel 1.

\begin{tabular}{|c|c|c|c|c|}
\hline Komposit & Al7Si (gram) & Mg (gram) & $\mathrm{SiC}$ (gram) & Total (gram) \\
\hline $\mathrm{Al7Si}$ & 1000 & - & - & 1000 \\
\hline $\mathrm{Al} 7 \mathrm{Si}+\mathrm{SiC} 5 \%$ & 950 & - & 50 & 1000 \\
\hline $\mathrm{Al} 7 \mathrm{Si}+\mathrm{SiC} 7,5 \%$ & 925 & - & 75 & 1000 \\
\hline $\mathrm{Al}$ Si+SiC $10 \%$ & 900 & - & 100 & 1000 \\
\hline Al7Si1Mg & 990 & 10 & - & 1000 \\
\hline $\mathrm{Al} / \mathrm{Si} 1 \mathrm{Mg}+\mathrm{SiC} 5 \%$ & 940,5 & 9,5 & 50 & 1000 \\
\hline Al7Si1Mg+SiC 7,5\% & 915,75 & 9,25 & 75 & 1000 \\
\hline $\mathrm{A} 17 \mathrm{Si} 1 \mathrm{Mg}+\mathrm{SiC} 10 \%$ & 891 & 9 & 100 & 1000 \\
\hline
\end{tabular}

3) Bahan matrik (A17Si / Al7Si1Mg) kemudian dimasukkan ke dalam tungku peleburan stir casting, dan dipanaskan sampai suhu $700 \mathrm{oC}$ untuk mencapai kondisi cair sempurna. Setelah itu didinginkan sampai suhu 590oC untuk mencapai kondisi semi solid. Sementara itu SiC juga dipanaskan sampai suhu 500oC. Cetakan logam juga dipanaskan sampai suhu 200oC.

4) $\mathrm{SiC}$ yang sudah dipanaskan kemudian dimasukkan ke dalam tungku sedikit demi sedikit untuk dicampur dengan matriks semi solid. Pengadukan dengan stirrer dengan kecepatan putar 600 rpm dibantu dengan pengadukan manual dilakukan selama 5 menit agar terjadi dispersi yang homogen dan permukaan SiC terbasahi dengan baik oleh matrik.

5) Suhu kemudian dinaikkan sampai suhu penuangan yaitu 850 oC sambil terus dilakukan pengadukan. Dilanjutkan dengan penuangan pada cetakan yang sudah dipanaskan terlebih dahulu hingga 200oC. Pendinginan dilakukan pada suhu ruang.

6) Setelah hasil cor mencapai suhu runang dan padat, kemudian dilepaskan dari cetakan, dan bahan dipotong sesuai dengan ukuran spesimen pengujian.

Proses stir casting dijelaskan dengan melalui grafik waktu vs suhu sebagaimana tercantum pada Gambar 1. Setup pengaduk dalam proses stir casting bisa dilihat pada Gambar 2.

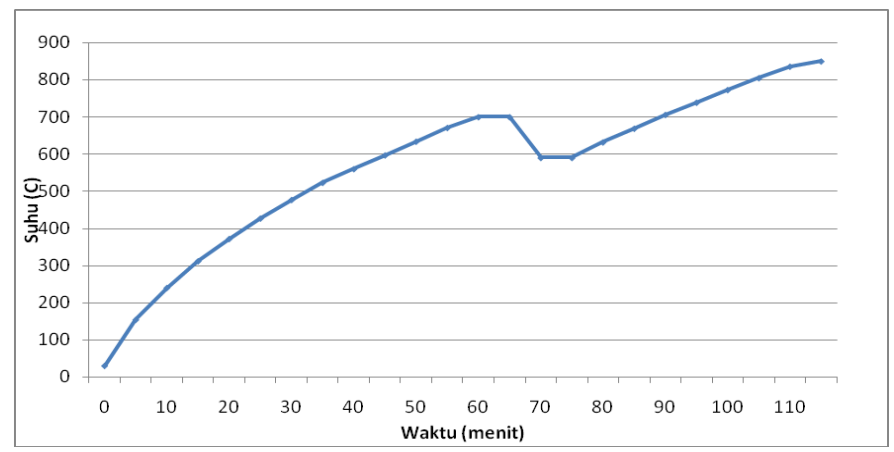

Gambar 1. Grafik waktu vs suhu proses stir casting

\subsection{Pengujian Tarik dan Impak}

Pengujian tarik dilakukan dengan berpedoman standar pengujian ASTM E 8M-04 [13]. Dalam pengujian ini akan didapatkan kurva tegangan-regangan. Dari kurva tersebut akan dicari luas daerah di bawah kurva yang merupakan nilai ketangguhan material. Uji Impak dilakukan dengan standar ASTM E23 02a [5]. Jenis pengujian yang dilakukan adalah CHARPY dengan spesimen seperti tipe A. Nilai 
ketangguhan material adalah besar energi yang diserap selama pengujian, yang dihitung dari besarnya selisih sudut awal dan sudut akhir pendulum. Harga impak adalah energi yang diserap dibagi dengan luas penampang patahan spesimen.

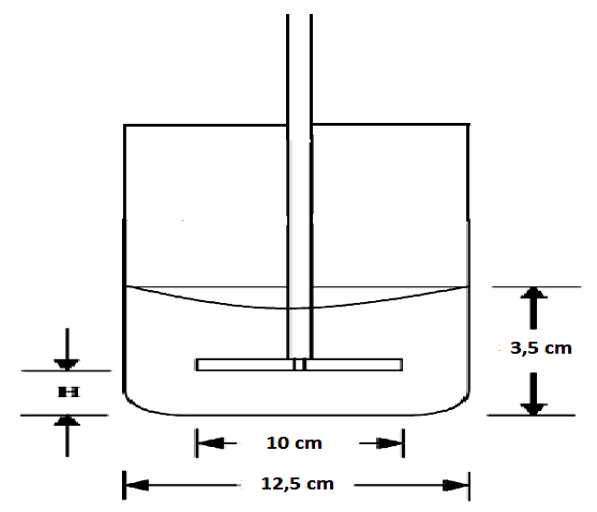

Gambar 2. Setup pengaduk pada proses stir casting. Ketinggian pengaduk (H) dibuat naik turun

\section{DATA DAN ANALISA}

\subsection{Nilai Ketangguhan Material Hasil Uji Tarik}

Uji tarik dilaksanakan di Laboratorium Material Teknik Jurusan Teknik Mesin Universitas Diponegoro dengan berpedoman pada ASTM E 8M-04. Hasil uji tarik berupa kurva tegangan reganganbisa dilihat pada Gambar 3.

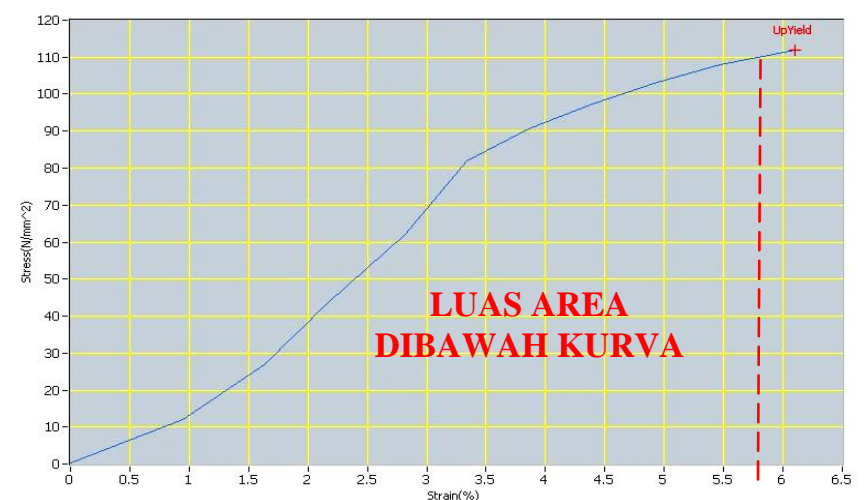

Gambar 3. Luasan di bawah kurva tegangan-regangan

Kurva tegangan-regangan kemudian digunakan untuk mencari luas daerah di bawah kurva dengan metode trapesium. Harga ketangguhan yang dihasilkan adalah energi per satuan volume (Joule/ $\left.\mathrm{cm}^{3}\right)$. Harga ketangguhan dari masing-masing ditunjukkan pada Tabel 2. Ketangguhan dari masing-masing komposisi adalah hasil rata-rata dari tiga hasil pengujian tarik.

Tabel 2. Harga ketangguhan hasil uji tarik

\begin{tabular}{lc}
\hline Komposit & Ketangguhan $\left(\mathbf{J} / \mathbf{c m}^{3}\right)$ \\
\hline Al7Si & 3,68 \\
Al7Si+5\%SiC & 4,6 \\
Al7Si+7,5\% SIC & 1,45 \\
Al7Si+10\%SiC & 1,02 \\
Al7Si1Mg & 4,07 \\
Al7Si1Mg+5\%SiC & 4,92 \\
Al7Si1Mg+7,5\% SIC & 2,57 \\
Al7Si1Mg+10\%SiC & 1,43 \\
\hline
\end{tabular}

Data ketangguhan material masing-masing variasi kemudian dibuat grafik hubungan antara penambahan persentase SiC dengan sifat ketangguhan material. 


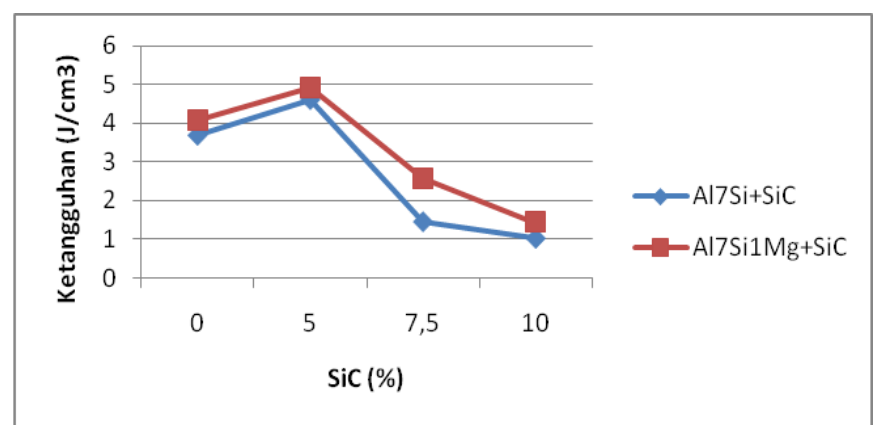

Gambar 4. Grafik hubungan antara \%SiC dengan ketangguhan AMC

Gambar 4. menunjukkan bahwa ketangguhan Al7Si mengalami peningkatan dengan adanya penambahan $1 \% \mathrm{Mg}$, yaitu naik sekitar $11 \%$. Ketangguhan material juga meningkat dengan penambahan $5 \% \mathrm{SiC}$, yaitu meningkat $25 \%$ pada $\mathrm{Al} 7 \mathrm{Si}+5 \% \mathrm{SiC}$, dan ketangguhan meningkat $21 \%$ pada Al7Si1Mg+5\%SiC. Penurunan ketangguhan terjadi seiring dengan penambahan SiC lebih dari 5\%. Sifat ketangguhan ini sejalan dengan sifat tarik lainnya dimana kekuatan tarik meningkat pada penambahan $\mathrm{SiC} 5 \%$ namun kemudian turun pada penambahan $\mathrm{SiC}$ lebih dari 5\%. Sementara itu nilai regangan menurun dengan penambahan persentase SiC. Dengan demikian luasan daerah di bawah kurva naik pada penambahan $5 \% \mathrm{SiC}$ dan kemudian menurun dengan penambahan $\mathrm{SiC}$ diatas $5 \%$.

\subsection{Perubahan Harga Impak sebagai Hasil Penambahan SiC}

Pengujian impak dilakukan di Laboratorium Bahan Teknik D3 Teknik Mesin Universitas Gajah Mada. Spesimen yang disiapkan untuk masing-masing variasi adalah 3 spesimen. Pelaksanaan uji impak berdasarkan standar ASTM E-23 02a. Hasil pengujian bisa dilihat pada Tabel 3. Data yang disajikan adalah nilai rata-rata dari tiga nilai hasil uji impak.

Tabel 3. Hasil uji impak

\begin{tabular}{lc}
\hline Komposit & Harga Impak $\left(\mathbf{J} / \mathbf{c m}^{2}\right)$ \\
\hline $\mathrm{Al} 7 \mathrm{Si}$ & 3,81 \\
$\mathrm{Al} 7 \mathrm{Si}+5 \% \mathrm{SiC}$ & 4,37 \\
$\mathrm{Al} 7 \mathrm{Si}+7,5 \% \mathrm{SIC}$ & 3,83 \\
$\mathrm{Al} 7 \mathrm{Si}+10 \% \mathrm{SiC}$ & 3,59 \\
$\mathrm{Al} 7 \mathrm{Si} 1 \mathrm{Mg}$ & 3,79 \\
$\mathrm{Al} 7 \mathrm{Si} 1 \mathrm{Mg}+5 \% \mathrm{SiC}$ & 4,73 \\
$\mathrm{Al} 7 \mathrm{Si} 1 \mathrm{Mg}+7,5 \% \mathrm{SIC}$ & 4,53 \\
$\mathrm{Al} 7 \mathrm{Si} 1 \mathrm{Mg}+10 \% \mathrm{SiC}$ & 4,59 \\
\hline
\end{tabular}

Data pada Tabel 3. kemudian dibuat grafik hubungan antara harga impak dengan persen SiC. Grafik hubungan tersebut ditunjukkan pada Gambar 5.

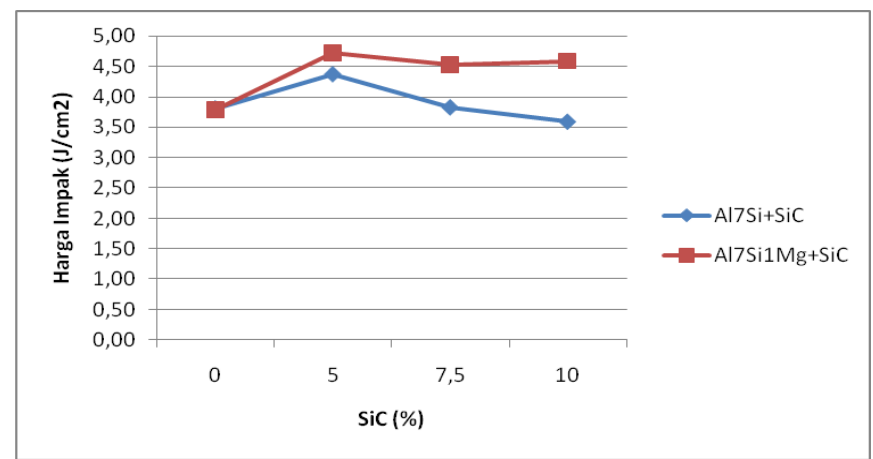

Gambar 5. Perubahan harga impak sebagai hasil penambahan SiC

Grafik pada Gambar 5. Menunjukkan bahwa harga impak komposit Al7Si1Mg + SiC lebih tinggi dibanding komposit $\mathrm{Al7Si}+\mathrm{SiC}$ untuk semua variasi persentase SiC. Harga impak tertinggi diperoleh 
pada penambahan 5\% $\mathrm{SiC}$ baik untuk komposit tanpa ataupun dengan penambahan unsur $\mathrm{Mg}$. Namun harga impak tertinggi sebesar $4,73 \mathrm{~J} / \mathrm{cm}^{3}$ diperoleh dengan penambahan $\mathrm{Mg} 1 \%$ dan $\mathrm{SiC} 5 \%$.

Kedua metode untuk mendapatkan nilai ketangguhan material yaitu dengan pengujian impak maupun luasan kurva tegangan-regangan hasil uji tarik terdapat kesamaan dan perbedaan. Kesamaannya adalah dengan penambahan $1 \% \mathrm{Mg}$ mampu meningkatkan ketangguhan, dan nilai ketangguhan tertinggi sama-sama dicapai pada penambahan 5\% SiC. Penambahan SiC lebih dari 5\% sama-sama menurunkan ketangguhan, namun penurunan ketangguhan yang diperoleh dari perhitungan kurva tegangan-regangan lebih ekstrim dibandingkan dengan penurunan ketangguhan pada uji impak. Fenomena ini terjadi karena pada pengujian tarik terjadi deformasi plastis pada spesimen atau diakomodasinya perhitungan energi yang di serap dalam deformasi per satuan volum. Sedangkan pada pengujian impak, kondisi yang diupayakan adalah terjadinya patah tanpa adanya deformasi plastis di sekitar patahan, atau tidak mengakomodasi energi yang diserap untuk terjadinya deformasi plastis per satuan volume. Dengan demikian material AMC berpenguat SiC lebih tangguh untuk menerima beban impak dibanding dengan beban tarik.

Penelitian sebelumnya menyatakan bahwa peningkatan persentase SiC akan meningkatkan meningkatkan ketangguhan impak. Pada penelitian ini kenaikan harga impak dicapai hingga penambahan $\mathrm{SiC} 5 \%$, sedanghan harga impak menurun dengan penambahan SiC lebih dari 5\%. Dari data tersebut bisa dianalisa bahwa penambahan $\mathrm{Mg} 1 \%$ hanya efektif untuk menaikkan wettability matriks $\mathrm{Al}$ terhadap SiC sampai 5\%. Penambahan $\mathrm{Mg}$ lebih dari $1 \%$ diperlukan untuk mempertahankan wettability pada penambahan SiC lebih dari 5\%.

\section{KESIMPULAN}

1) Penambahan $1 \% \mathrm{Mg}$ mampu meningkatkan ketangguhan, dan nilai ketangguhan tertinggi dicapai pada penambahan $5 \% \mathrm{SiC}$

2) Penambahan $\mathrm{SiC}$ lebih dari $5 \%$ menurunkan ketangguhan

3) Penambahan $\mathrm{Mg} 1 \%$ hanya efektif untuk menaikkan wettability matriks Al terhadap SiC sampai 5\%. Penambahan $\mathrm{Mg}$ lebih dari $1 \%$ diperlukan untuk mempertahankan wettability pada penambahan $\mathrm{SiC}$ lebih dari $5 \%$.

\section{DAFTAR PUSTAKA}

[1] Sahin, Y., and Murphy, S. (1996). "The Effect of Fibre Orientation of The Dry Sliding Wear of Borsic Reinforced Aluminium Alloy”. S. Mater Sci 34, 5399-5407.

[2] Taha, MA., and El-Mahallawy, NA. (1993). “Advances in Metal Matrix Composites". Key Engineering Materials 79-80, 75-90.

[3] Hashim, J., et al. (2001). "The Wettability of SiC Particle in Cast Aluminium Matrix Composites". Journal of Material Processing Technology 119, 329-335.

[4] Roylance, D. (2001). "Stress-Strain Curve", Dept. of Materials Science and Engineering, Cambridge.

[5] ASTM E-23. (2003). Standard Test Methods for Notched Bar Impact Testing of Metallic Materials.

[6] Soe, YH., and Kang, CG. (1995). "The Effect of Aplied Pressure on Particle Dispersion Characteristic and Mechanical Properties in Melt Stiring Squeeze Cast SiC/Al Composites”. J. Mater Process, Technol. 55, 370379.

[7] Viswanatha, BM.., et al. (2013). "Mechanical Properties Evaluation of A356/SiCp/Gr Metal Matrix Composites". Journal of Engineering Science and Technology 8.6, 754-763.

[8] Ozben, T., et al. (2008). "Investigation Mechanical and Machinability Properties of SiC Particle Reinforced Al-MMC”. Journal of Materials Processing Technology 1.98, 220-225e.

[9] Meena, K.L., Manna, A., Banwait, SS. (2013). “An Analysis of Mechanical Properties of The Developed $\mathrm{Al} / \mathrm{SiC}-\mathrm{MMC}$.' American Journal of Mechanical Engineering 1.1, 14-19.

[10] Manoj, S., Dwivwli, D., Singh, L. (2009). "Development of Aluminium Based Silicon Carbide Particulate Matal Matrix Composites”. Journal of Mineral and Materials Characterization and Engineering 8.6, 455467.

[11] Singh, G., and Kalra, CS. (2014). "Fabrication and Characterization of Al Based Hybrid Composites Reinforced With SiC, AL2O3, and C Particles by Squeeze Casting”. Mechanica Confab 3, 1-9.

[12] Zehraa, N., and Ameer, A. (2013). "Studying Some of Mechanical and Thermal Properties of Al-SiC composites", Journal of Al-Nahrain University 16.2, 119-123.

[13] ASTM E 8M-04. (2004). Standard Test Methods for Tension Testing of Metallic Materials. 